\title{
Vulneración de principios fundamentales mediante la interposición de la acción de tutela contra providencia judicial
}

\section{Breach of civil rights by presenting protection of civil rights action against judicial providence}

\author{
LINDA ELENA NADER ORFALE \\ Abogada. Docente de la Facultad de Jurisprudencia de la Universidad Autónoma del Caribe. \\ linda.nader@uac.edu.co
}

Recibido: Septiembre 3 de 2013

Aceptado: Noviembre 13 de 2013

\begin{abstract}
La acción de tutela es un mecanismo jurídico que tiene como propósito primordial el amparo de los derechos fundamentales contemplados en la Carta Nacional. La Corte Constitucional, que es la entidad encargada de velar por la integridad y la supremacía de la Constitución, ha desarrollado una doctrina jurisprudencial alrededor del tema de la tutela contra providencias judiciales, la cual ha ido evolucionando a través del tiempo, estableciendo unas causales de procedibilidad, que ha dividido en dos, las genéricas y las específicas.. Es importante conocer la evolución jurisprudencial que se ha dado en torno a la presente temática, puesto que la acción de tutela es un instrumento que tienen todos los ciudadanos para proteger sus derechos fundamentales. Asimismo se hace necesario indicar como la acción de tutela contra providencias judiciales puede llegar a vulnerar diversos principios fundamentales como son la seguridad jurídica, non bis in idem, celeridad y autonomía e independencia judicial, y a su vez realizar un análisis comparativo con las posiciones que defienden la tutela contra sentencias, las cuales establecen que ésta no viola ninguno de los principios mencionados.

Palabras Clave Acción de tutela, providencias judiciales, Corte Constitucional, causales de procedibilidad, principios fundamentales.
\end{abstract}

\begin{abstract}
The Civil Rights protection action is a legal mechanism that has a main purpose. This purpose is the protection of the fundamental rights enshrined in the National Constitution. The Constitutional Court, which is the Agency responsible for ensuring the integrity and supremacy of the Constitution, has developed around the issue of the protection of civil rights action against court orders. This action has evolved over time, establishing a causal procedural, which has split into two, the generic and specific actions. It is important to know the jurisprudential developments that have been around this topic, since the civil rights protection action is an instrument that all citizens have to protect their fundamental rights. It is necessary also indicate how this action against court orders may violate some fundamental principles as are the legal certainty, non bis in idem, speedy and autonomy and independence of the judiciary, and in turn carry out a comparative analysis of the positions that defend the Civil Rights protection action against sentences, which stipulate that this does not infringe on any of the above mentioned principiples.

Key Words: Civil Rights protection action, judicial providence, the Constitutional Court, Causal procedural, fundamental principles.
\end{abstract}




\section{Antecedentes de la acción de tutela.}

La acción de tutela proviene de la legislación española, donde es conocida como derecho de amparo, el cual se encuentra contemplado en la Constitución de 1978. El derecho de amparo y la acción de Tutela poseen similitudes y diferencias, entre las similitudes se encuentra el hecho de que las dos son recursos extraordinarios, preferenciales y sumarios para la defensa de los derechos fundamentales, y la diferencia entre ambas, es que en España esta acción es conocida por el Tribunal Constitucional Español, de manera directa, después de haberse agotado las vías judiciales ordinarias, mientras que en Colombia la acción de Tutela es de conocimiento de todos los jueces de la República.

En el ordenamiento constitucional colombiano no se registran antecedentes de la acción de tutela, con excepción de algunas expresiones en el plano de la jurisdicción de lo contencioso administrativo, como es el caso de la suspensión de los actos administrativos por razones constitucionales en caso de evidente y clara violación al ordenamiento superior y por otro lado los efectos abinitio o de anulación de los actos administrativos inconstitucionales. Cabe resaltar que el Consejo de Estado en su jurisprudencia ha definido que la suspensión provisional se encuentra condicionada a que el acto acusado contraríe de forma clara, ostensible, flagrante o manifiesta lo dispuesto en normas superiores, y que este requisito se debe constatar con el simple cotejo de las normas que se confrontan.

En Colombia la acción de tutela no aparece contemplada en la Constitución de 1886, ésta fue establecida por la Asamblea Nacional Constituyente de 1991, como una de las más importantes creaciones de la nueva organización constitucional; "allí se introdujo la institución, se definió su naturaleza, su finalidad y sus más importantes elementos procesales, y todo esto se hizo sin grandes deliberaciones jurídicas internas y sin ningún debate externo, previo o simultaneo". (Asamblea Nacional Constituyente, Gaceta Constitucional No. 116).

\section{Características de la acción de tutela}

Con la Constitución Política de 1991 los derechos humanos eran por primera vez positivizados y declarados como derechos fundamentales inherentes a la persona, por lo que ésta realizó una extensa declaración de los derechos, clasificándolos en tres categorías: fundamentales; económicos, sociales y culturales; y colectivos y del medio ambiente. Para los derechos fundamentales la Carta Nacional estableció la mencionada acción de tutela, con el fin de que las personas puedan solicitar por esta acción la protección de los derechos mencionados, cuando alguno de ellos haya sido vulnerado o se encuentra en una situación inminente de violación.

La Corte Suprema de Justicia ha afirmado que la tutela es el mayor legado del constituyente de 1991, la institución que merece el reconocimiento de la excelencia en la construcción del Estado Social, el mecanismo más eficiente para hacer realidad el acceso a la administración de justicia. A partir de lo anterior se puede inferir que la tutela tiene bien habido prestigio cuando acredita cumplir con la finalidad para la que la consagró el artículo 86 de la Constitución Política: instalar de manera expedita a innumerables ciudadanos en el goce de los derechos fundamentales vulnerados por las autoridades administrativas o los particulares.

La Corte Constitucional a lo largo de los años ha elaborado una doctrina que permite que en ciertas circunstancias algunos de los derechos que no han sido clasificados como fundamentales, puedan protegerse también a través de la acción de tutela. Según el alto tribunal

...El que un derecho sea fundamental no se puede determinar sino en cada caso en concreto, según la relación que dicho caso tenga con uno $\mathrm{u}$ otro derecho fundamental; es decir, la Constitución no determina de una manera clara cuáles son los derechos fundamentales. ${ }^{1}$

A partir de lo anterior se puede afirmar que según la jurisprudencia, no se puede considerar únicamente como derechos fundamentales los establecidos en el Capítulo I del Título II de la Carta Nacional.

\section{Causales de procedibilidad de la acción de tutela contra providencias judiciales}

La Corte Constitucional ha considerado en sus fallos, que la tutela contra sentencias judiciales sólo procede cuando se puede calificar la actuación del juez como una vía de hecho. Por lo tanto se hace necesario conocer la definición de vía de hecho. La Corte Constitucional, ha entendido como vías de hecho:

...aquellas actuaciones arbitrarias que el funcionario judicial desarrolla dentro de la dirección y sustanciación de un proceso. Por consiguiente, suceden estas circunstancias cuando el juez se aparta de la ley, con lo cual vulnera derechos constitucionales fundamentales" (Sentencia SU-542 de 1999).

\footnotetext{
Véase: Corte Constitucional: Sentencia T- 451 de Julio 10 de 1992.
} 
...Las garantías que integran el debido proceso deben preservarse íntegramente, de lo cual se infiere que la falta de cualquiera de ellas repercute en la pérdida de validez de lo actuado, y puede constituir-depende de su gravedad- una vía de hecho susceptible de la acción de tutela"(Corte Constitucional. Sentencia SU- 960 de 1999).

Sin embargo es importante resaltar que la expresión "vías de hecho" ha sido revaluada por la Corte Constitucional, y por esta razón se ha cambiado la denominación a "causales de procedibilidad de la tutela contra sentencias". La Corte Constitucional ha establecido estos requisitos con la finalidad de que el juez constitucional pueda conocer de fondo sobre una tutela contra una sentencia judicial.

Existen unas causales genéricas de procedibilidad de la tutela contra sentencias judiciales y unas causales específicas.

La Corte Constitucional ha expresado sobre las causales genéricas que éstas hacen referencia a los requisitos que posibilitan la interposición de la acción, las cuales son las siguientes:

1) Que la cuestión que se discuta resulte de evidente relevancia constitucional

Sobre este requisito la Corte Constitucional ha señalado que el juez constitucional no tiene competencia para estudiar asuntos de mera legalidad que no tengan relación directa y evidente con el contenido constitucionalmente protegido de los derechos fundamentales. De esta manera la Corte pretende evitar que la acción de tutela se convierta en una nueva instancia o que termine reemplazando los recursos ordinarios o extraordinarios propios del proceso ordinario ${ }^{2}$.

2) Que se hubieren agotado todos los mecanismos ordinarios y extraordinarios de defensa judicial al alcance de la persona afectada, salvo que se trate de evitar la consumación de un perjuicio iusfundamental irremediable.

Es importante establecer que la acción de tutela contra providencias judiciales no es un mecanismo alternativo ni accesorio.

Por lo tanto, este requisito hace referencia a que el afectado debió haber agotado todos los medios de defensa dentro del proceso ordinario, para así poder interponer acción de tutela contra una sentencia judicial. Sin

\footnotetext{
Véase: Corte Constitucional: Sentencias T-173/1993 y T-685/2003.
}

embargo esta causal presenta dos excepciones, que son las siguientes:

- Cuando la persona no interpuso los medios de defensa por razones completamente ajenas a su voluntad, es decir que el afectado no actúo por negligencia o descuido.

- Cuando el afectado acude a la acción de tutela como mecanismo transitorio para evitar un perjuicio irremediable.

3) Que la parte actora identifique de manera razonable tanto los hechos que generaron la vulneración como los derechos vulnerados y que hubiere alegado tal vulneración en el proceso judicial siempre que esto hubiere sido posible:

Este requisito es propio de la tutela contra sentencias judiciales, pues la Corte ha señalado en diversas ocasiones que en la acción de tutela el demandante no tiene obligación de probar los hechos que pone de presente, ni de indicar los derechos que encuentra violados, ni de aportar razones claras y suficientes para explicar la violación de que da cuenta ${ }^{3 \prime}$.

...Además este requisito tiene como finalidad el evitar la posible desviación con respecto al tema de debate, por lo tanto es fundamental que el actor identifique los hechos que originaron la violación y una enunciación sucinta de los derechos violados.

Esta exigencia es comprensible pues, es menester que el actor tenga claridad en cuanto al fundamento de la afectación de derechos que imputa la a la decisión judicial, que la haya planteado al interior del proceso y que dé cuenta de todo ello al momento de pretender la protección constitucional de sus derechos ${ }^{4}$.

4) Que la acción u omisión judicial que acusa el actor de violar sus derechos fundamentales hubiere tenido, o pueda tener, un efecto directo, sustancial y determinante sobre la sentencia judicial respectiva:

Cuando se trate de una irregularidad procesal, debe quedar claro que la misma tiene un efecto decisivo o determinante en la sentencia que se impugna y que afecta los derechos fundamentales de la parte actora.

Sobre este requisito la Corte Constitucional estableció en la sentencia C-590/2005, que esta regla no es aplicable

\footnotetext{
Véase: Corte Constitucional. Sentencia T-654/1998.

Véase: Corte Constitucional. Sentencia C-590 de 2005.
} 
cuando se trata de actuaciones procesales que comporten una lesión grave y evidente de los derechos fundamentales, como por ejemplo, la prueba obtenida bajo tortura.

5) Que se cumpla el requisito de la inmediatez, es decir, que la tutela se hubiere interpuesto en un término razonable y proporcionado a partir del hecho que originó la vulneración:

La Corte Constitucional ha establecido que, en principio, la tutela que es entablada después de haber transcurrido más de un año desde la notificación de la decisión judicial respectiva, no satisface la regla de la inmediatez.

Para este requisito existe una excepción y es cuando el actor logra comprobar que se encontraba en absoluta incapacidad de ejercer sus derechos, como es el caso de una persona secuestrada. $\mathrm{Al}$ respecto la Corte Constitucional ha establecido, que para determinar la procedencia de la acción de tutela, en relación con la regla de la "inmediatez", se debe señalar, entre otros elementos, que el juez constitucional debe constatar si existe un motivo válido para la inactividad de los accionantes.

Por lo tanto es importante concluir que de permitir que la acción de tutela proceda meses o aún años después de proferida la decisión, se sacrificarían los principios de cosa juzgada y seguridad jurídica ya que sobre todas las decisiones judiciales se cerniría una absoluta incertidumbre que las desdibujaría como mecanismos institucionales de resolución de conflictos.

6) Que la acción no se interponga contra una sentencia de tutela.

La Corte Constitucional ha establecido que dicha prohibición se realiza con el fin de evitar que los debates sobre la protección de los derechos fundamentales se prolonguen de manera indefinida, atendiendo además el hecho de que todas las sentencias proferidas son sometidas a un riguroso proceso de selección ante la Corte Constitucional.

Tal y como se mencionó anteriormente existen también unas causales específicas de procedibilidad de la tutela contra sentencias judiciales las cuales se centran en el estudio de la providencia que se ataca en sede de amparo y en las deficiencias que debe tener para que materialmente la acción prospere.

Las causales específicas de procedibilidad que de conformidad con la doctrina constitucional actual se han establecido, son las siguientes:

1) Defecto procedimental absoluto:
La Corte Constitucional ha establecido que para que se configure la vía de hecho por defecto procesal es necesario que la violación del procedimiento sea grave y evidente; que el desconocimiento del procedimiento tenga un efecto importante sobre los derechos procesales o sustantivos de la persona afectada; y que la irregularidad no se deba a una acción u omisión del afectado.

Así, por ejemplo, según la Corte Constitucional, está viciado todo proceso en el que se omiten eventos o etapas señaladas en la ley para poder asegurar el ejercicio de todas las garantías que se le reconocen a los sujetos procesales de forma tal que, por ejemplo,

- Puedan ejercer el derecho a una defensa técnica, que supone la posibilidad de contar con la asesoría de un abogado- en los eventos en que sea necesario-, ejercer el derecho de contradicción y presentar y solicitar las pruebas que considere pertinentes para sustentar su posición.

- Se les comunique de la iniciación del proceso y se permita su participación en el mismo.

- Se les notifiquen todas las providencias proferidas por el juez, que de acuerdo con la ley, deben serles notificadas.

2) Defecto orgánico o falta de competencia:

Este defecto se produce cuando el funcionario judicial que desarrolla el procedimiento o que profiere la correspondiente decisión carece absolutamente de competencia para hacerlo ${ }^{5}$. Para que se cumpla esta causal la Corte Constitucional ha considerado que se deben cumplir estos requisitos:

- No exista atribución alguna de competencia

- Que la norma que asigna la competencia sea manifiestamente contraria a derecho.

Si un funcionario de la jurisdicción ordinaria falla un proceso que corresponde a la jurisdicción contencioso administrativa, incurre en una ostensible vía de hecho, no justificable por el silencio de las partes o por la desidia del mismo juez de plantear en cualquier instancia procesal la nulidad insanable de falta de jurisdicción ${ }^{6}$.

Es importante señalar también que la Corte Constitucional ha expresado que la existencia de un juez competente no solamente surge del ordenamiento nacional sino de disposiciones internacionales aplicables a Colombia,

\footnotetext{
Véase: Sentencias T-668/1997 y T.008/1998.

Véase: Corte Constitucional. Sentencia T-668 de 1997.
} 
con carácter prevalente, como es el caso de la Convención Americana sobre Derechos Humanos.

3) Defecto fáctico:

Surge cuando el juez carece del apoyo probatorio que permita la aplicación del supuesto legal en el que se sustenta la decisión.

Para que prospere la acción de tutela por defecto fáctico es necesario que la prueba que se recauda o valora arbitrariamente resulte evidentemente determinante para la adopción de la decisión final, esto es que "sin tal elemento probatorio no hubiera sido posible adoptar la sentencia que se impugna o que su práctica o valoración hubieren cambiado necesariamente el curso del proceso" ${ }^{\prime 7}$.

El defecto fáctico absoluto puede tener origen, a su turno, en dos tipos de vicios o defectos. El defecto fáctico omisivo y el defecto fáctico positivo ${ }^{8}$. El defecto fáctico omisivo se origina en los casos en que el juez ha dejado de actuar. Se puede producir bien cuando el juez ha dejado de decretar una prueba determinante para el proceso o cuando habiéndose decretado y practicado la prueba, ha omitido completamente su valoración. La segunda dimensión del defecto es la positiva, es decir, aquella que se presenta cuando el juez ha actuado, ha decretado o valorado la prueba pero su actuación es abiertamente arbitraria. En concreto, sucede cuando se han apreciado pruebas que no se han debido admitir ni valorar, porque a raíz de un acto arbitrario no pudieron ser controvertidas por la parte concernida o porque fueron recaudadas con violación del debido proceso.

Cabe resaltar que se constituye defecto fáctico absoluto cuando la práctica o valoración de una prueba, haya sido obtenida con grave y evidente violación de la dignidad humana.

\section{4) Error inducido o por consecuencia:}

En criterio de la Corte para que se configure una vía de hecho por consecuencia es necesario que "la decisión judicial se base en la apreciación de hechos o situaciones jurídicas, en cuya determinación los órganos competentes hayan violado derechos constitucionales, y que tenga como consecuencia un perjuicio iusfundamental" ${ }^{\prime \prime}$. Esta causal hace referencia a aquellos casos en los que el funcionario judicial ha sido inducido al error y ha actuado

Véase: Corte Constitucional. Sentencia T-538 de 1994.

Véase: Corte Constitucional: Sentencia SU-159 de 2002.

Véase: Corte Constitucional. Sentencia T-705 de 2002. guiado por la confianza en una actuación estatal previa, actuación que a su turno resulta inconstitucional.

5) Defecto material o sustantivo:

"El defecto sustantivo que convierte en vía de hecho una sentencia judicial, opera cuando la decisión que toma el juez desborda el marco de acción que la Constitución y la ley le reconocen al apoyarse en una norma evidentemente inaplicable al caso concreto" $^{\prime 10}$, bien sea por:

- La norma ha sido derogada y ya no produce ningún efecto en el ordenamiento jurídico.

- Cuando la norma aplicable al caso es evidentemente inadvertida o tenida en cuenta por el fallador.

- La norma es claramente inconstitucional y el funcionario se abstuvo de aplicar la excepción de inconstitucionalidad.

- La aplicación de la norma al caso concreto es inconstitucional.

- La norma ha sido declarada inexequible por la propia Corte Constitucional.

- Porque a pesar de estar vigente y ser constitucional, no se adecua a la circunstancia fáctica a la cual se aplicó, porque a la norma aplicada, por ejemplo, se le reconocen efectos distintos a los expresamente señalados por el legislador.

- Cuando a pesar del amplio margen interpretativo que la Constitución le reconoce a las autoridades judiciales, la aplicación final de la regla es inaceptable por tratarse de una interpretación contra-evidente o claramente perjudicial para los intereses legítimos de una de las partes.

6) Violación directa de la Constitución:

Esta causal se origina porque el juez desconoce el contenido de los derechos fundamentales de alguna de las partes, o realiza interpretaciones inconstitucionales o no utiliza la excepción de inconstitucionalidad ante vulneraciones protuberantes de la Carta.

Con respecto a esta causal la Corte Constitucional ha establecido lo siguiente:

...Violación directa de la Constitución, se estructura cuando el juez ordinario adopta una decisión que desconoce, de forma específica, postulados de la Carta Política. El actual modelo de ordenamiento constitucional reconoce valor normativo a los preceptos superiores, de modo tal que contienen mandatos $y$

${ }^{10}$ Véase Corte Constitucional. Sentencia T-597 de 2011 
previsiones de aplicación directa por las distintas autoridades. ${ }^{11}$

7) Desconocimiento del precedente:

El desconocimiento del precedente se origina cuando el juez toma una decisión apartándose del precedente jurisprudencial de tal forma que si se hubiera ajustado al precedente la decisión habría sido diferente.

El desconocimiento del precedente ha adquirido un gran valor en la actualidad colombiana, el cual se ve reflejado en el nuevo Código de Procedimiento Administrativo y de lo Contencioso administrativo, que establece la extensión de la jurisprudencia cuando se trate de un mismo asunto.

8) Decisión judicial sin motivación:

La decisión judicial sin motivación se origina cuando la autoridad judicial profiere su decisión sin argumentarla debidamente o los motivos para dictar la sentencia no son relevantes en el caso concreto. La Corte Constitucional ha señalado que esta causal implica el incumplimiento de los servidores judiciales del deber de dar cuenta de los fundamentos fácticos y jurídicos de sus decisiones.

..."Sentencia sin motivación, que implica el incumplimiento de los servidores judiciales del deber de dar cuenta de los fundamentos fácticos y jurídicos de sus decisiones, pues precisamente en esa motivación reposa la legitimidad de su órbita funcional. Este tipo de falencia se distingue del defecto fáctico, en cuanto no se estructura a partir de la disconformidad entre la motivación de la sentencia y su parte resolutiva, sino en la ausencia de razonamientos que sustenten lo decidido. Es evidente que una exigencia de racionalidad mínima de toda actuación judicial es que exprese los argumentos que hacen inferir la decisión correspondiente. Cuando este ineludible presupuesto no puede verificarse, la sentencia contradice aspectos que parte del núcleo esencia del derecho fundamental al debido proceso.

Decisión sin motivación, implica el incumplimiento de los servidores judiciales de dar cuenta de los fundamentos fácticos y jurídicos de sus decisiones en el entendido que precisamente en esa motivación reposa la legitimidad de su órbita funcional" ${ }^{\prime 2}$.
Cabe resaltar que algunos tratadistas consideran que es casi imposible que un juez de la República incurra en una vía de hecho, o que su conducta se ajuste a una de estas causales, opinando que

vías de hecho es exactamente lo contrario de vías de derecho, decir por consiguiente de un funcionario judicial que ha incurrido en "vías de hecho" es como decir de un militar que ha fusilado a un prisionero sin fórmula de juicio ${ }^{13}$. (Gómez, H, 2012)

\section{Vulneración de principios fundamentales mediante la interposición de una acción de tutela contra providencia judicial.}

En este aparte se buscará establecer diversas posiciones que señalan como la interposición de una acción de tutela contra providencias judiciales puede entrar a vulnerar diversos principios fundamentales, asimismo se indicará las posturas que manifiestan que por el contrario ésta no viola principios, y que por el contrario se constituye en una garantía que tienen los ciudadanos cuando una decisión judicial afecta sus derechos fundamentales.

\section{a) Violación al principio de seguridad jurídica:}

La Corte Constitucional ha señalado acerca de la seguridad jurídica, que este es un principio central en los ordenamientos jurídicos occidentales, el cual ostenta rango constitucional, derivándolo del preámbulo de la Constitución y de los artículos 1, 2, 4,5 y 6 de la Carta Nacional.

En relación al tema de la vulneración de la seguridad jurídica frente a la procedencia de la acción de tutela contra providencias judiciales, la Corte Suprema de Justicia ha insistido en que es el órgano límite dentro de su respectiva jurisdicción, que sus fallos son intangibles e inmodificables, que sus decisiones hacen tránsito a cosa juzgada material y que se debe garantizar por tanto la seguridad jurídica (Unimedios. Universidad Nacional de Colombia).

Sin embargo los que se encuentran a favor de la procedencia de la acción de tutela contra providencias judiciales afirman que los principios de seguridad jurídica y cosa juzgada no son absolutos y por ello se hace necesario en caso de conflicto ponderarlo con derechos fundamentales.

3 La Acción de Tutela Contra Providencias Judiciales En Colombia. Historia De Una Farsa. Oscar Humberto Gómez.

www.oscarhumbertogomezgomez.com. 


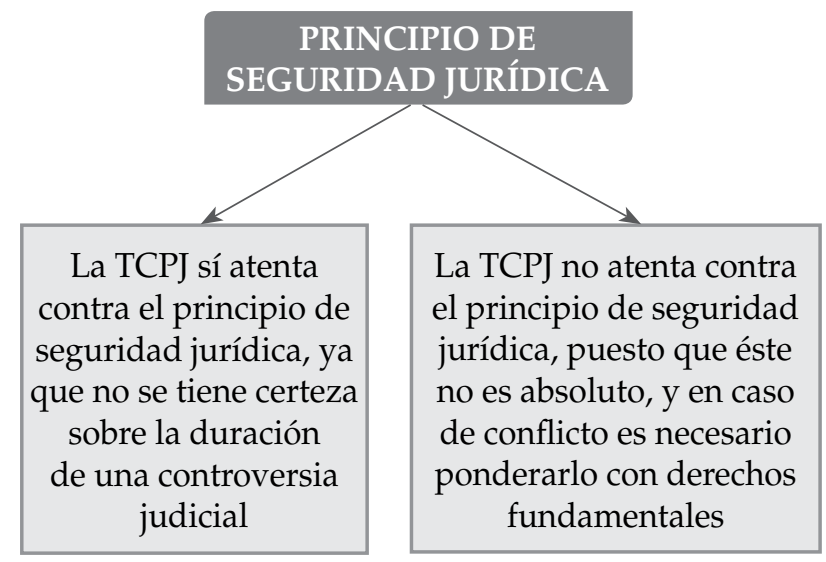

\section{b) Violación al principio de non bis in idem}

Los que se encuentran en contra de la tutela contra providencias judiciales afirman que ésta vulnera el principio del non bis ídem, por cuanto implicaría la reapertura de un proceso ya finalizado, por lo tanto no es procedente una nueva decisión sobre un asunto que ha sido resuelto.

Sin embargo los que se encuentran a favor de la tutela contra providencias judiciales establecen que ésta no vulnera el principio del non bis ídem puesto, que no se trata de enjuiciar a una persona, sino a una providencia proferida por un juez de la república que viola derechos fundamentales contemplados en la Constitución Política.

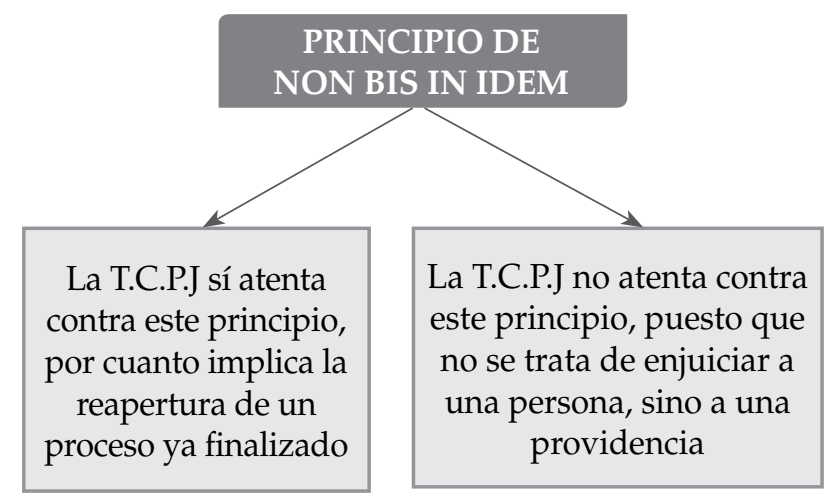

\section{c) Vulneración al principio de Celeridad.}

Los que se encuentran en contra de la acción de tutela contra providencias judiciales, manifiestan lo siguiente:

...La aceptación de la tutela contra sentencias conlleva a la afectación de los principios rectores de la administración de justicia, tal como la celeridad, "por cuanto este tipo de demandas incrementan el trabajo de los despachos judiciales, y por tanto, conducen a demoras en la resolución de los casos" (Herrera, p. 29).
Sin embargo los que se encuentran a favor de la acción de tutela contra providencias judiciales expresan que ésta no vulnera el principio de celeridad de la administración de justicia, puesto que no se tiene evidencia de que sea esta acción la que esté ocasionando la congestión de los despachos judiciales.

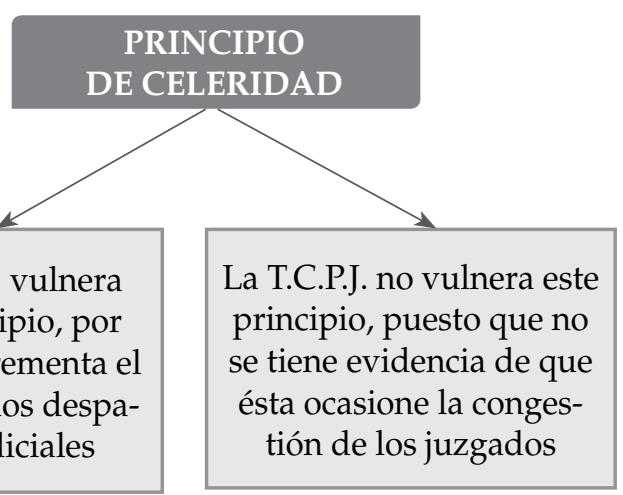

\section{d) Vulneración al principio de autonomía e independencia judicial.}

La Corte Suprema de Justicia ha manifestado en diversas ocasiones, que es el órgano límite de su jurisdicción, por lo que los jueces de tutela no pueden entrar a transformar la jerarquía establecida por la Carta Nacional del 91. Indicando además que la autonomía de los jueces no puede verse perturbada, ni aun pretextando la facultad de controlar la constitucionalidad de sus actos.

Los que se encuentran a favor de la acción de tutela contra providencias judiciales señalan que ésta no vulnera el principio de autonomía e independencia judicial puesto que estos principios deben entenderse en el contexto de la supremacía constitucional.

PRINCIPIO DE AUTONOMIA

E INDEPENDENCIA JUDICIAL

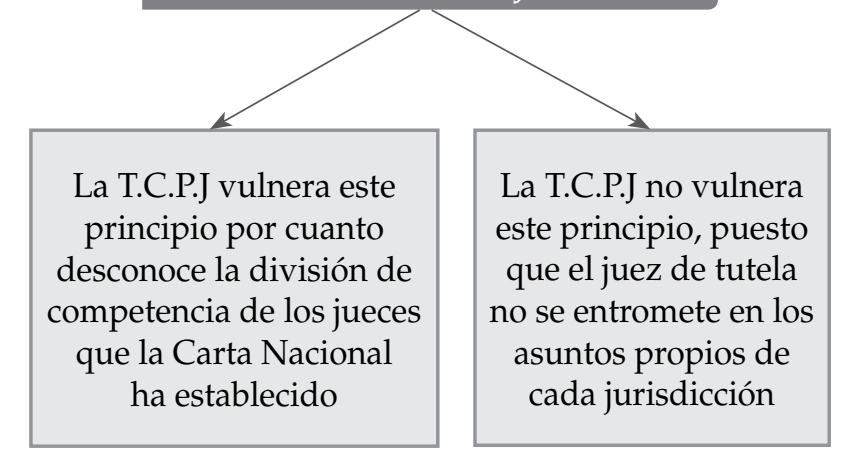

\section{Conclusión}

La Corte Constitucional ha establecido una doctrina jurisprudencial sobre el tema de la acción de tutela contra 
providencias judiciales, indicando unas causales de procedibilidad, que son totalmente acertadas, puesto que lo que se busca es precisamente, amparar los derechos fundamentales, que fueron contemplados en la Carta Nacional de 1991.

Este organismo estableció en un principio las vías de hecho, indicando que cuando en una sentencia se configurara una de estas vías, procedía la tutela contra providencias judiciales, sin embargo con el transcurso del tiempo la expresión "vía de hecho" fue revaluada por este organismo jurisdiccional al considerar que no era el término más adecuado, por lo que fue reemplazada por "causales genéricas de procedibilidad". Este cambio de denominación se produjo debido a que la Corte Constitucional ha decantado los conceptos de capricho y arbitrariedad judicial, en los que originalmente se fundaba la noción de vía de hecho y por el contrario ha incluido además aquellos casos en los que los jueces se apartan de los precedentes sin argumentar debidamente y cuando su discrecionalidad interpretativa se desborda en perjuicio de los derechos fundamentales de los asociados.

Sin embargo existen posturas que señalan que a pesar de que se configure una causal de procedibilidad establecida por la Corte Constitucional, la interposición de una acción de tutela contra providencia judicial puede llegar a afectar principios fundamentales como son la seguridad jurídica, el non bis in ídem, la celeridad y la autonomía e independencia judicial.

Pero por el contrario, la realidad es que estos principios fundamentales mencionados no son absolutos, $\mathrm{y}$ que la tutela contra providencias judiciales se convierte en una garantía que tienen los ciudadanos cuando una decisión judicial (auto y sentencia) vulnera derechos fundamentales.

\section{Referencias}

Araujo Renteria, J. (1992). Procedencia de la acción de tutela contra providencias judiciales. Conferencia dictada en la Universidad Externado de Colombia. Tercer encuentro de la Jurisdicción Constitucional. Bogotá.

Azula Camacho. (2000) Manual de Derecho Procesal. Bogotá: Editorial Temis.

Barreto Rodríguez, J. (1997.). Acción de Tutela. Teoría y Práctica. Bogotá: Editorial Legis.

Bernal Pulido, C. (2005) El derecho de los derechos escritos sobre la aplicación de los derechos fundamentales. Bogotá: Editorial Universidad Externado de Colombia.

Burgoa, I. (1997) Diccionario de Derecho Constitucional Garantías y Amparo. México: Editorial Porrúa.

Cifuentes Muñoz, E (1998) Tutela Contra Sentencias (El Caso Colombiano). Talca: Editorial Universidad de Talca.

Charry Urueña, J. (1992.) La Acción de Tutela. Bogotá: Editorial Temis.

De Santo, V. (1982) El proceso Civil. Buenos Aires: Editorial Universidad de Buenos Aires.

Dueñas Ruiz, O (1992). Acción de Tutela. Bogotá: Editorial Librería del Profesional.

Formisano M. (2003) .Cinco argumentos a favor del mantenimiento de la acción de tutela para los derechos económicos, sociales y culturales en Colombia. En: Tutela. Acciones populares y de cumplimiento. Bogotá: Editorial Legis.

Giacomette Ferrer, A (2008). La Prueba en los Procesos Constitucionales. México. Editorial Porrúa.

Gómez Serrano, L (1992.). Control Constitucional en Colombia: Evolución histórica. Bogotá: Editorial UNAB.

Gómez, O. (2012) La Acción de Tutela contra Providencias Judiciales en Colombia. Historia de una Farsa. Disponible en www. oscarhumbertogomez.com.

Henao Orozco, R (2006.). Tutela contra sentencias de las altas cortes o choque de vanidades. Bogotá: Editorial Universidad Militar Nueva Granada. 
Herrera Vergara, J (2006). La Reforma constitucional a la acción de tutela contra providencias judiciales. Bogotá: Editorial Universidad del Rosario.

López, H. (2001) Datos cuantitativos sobre la tutela. Cuánto, ante quiénes y donde (1999-2001). Observatorio de Justicia Constitucional. Derecho constitucional, perspectivas críticas. Bogotá: Legis Editores S.A.

Perez Restrepo, B (2003). La Acción de Tutela, Consejo Superior de la Judicatura. Bogotá: Editorial Universidad Nacional de Colombia.

Petit, E. (1954) Tratado elemental de derecho romano. Buenos Aires: Editorial Albatros.

Quinche Ramirez, M (2006). La acción de tutela contra providencias judiciales. La necesidad de una reforma que no sacrifique los derechos fundamentales. Bogotá: Editorial Universidad del Rosario.

Quiroga N, (2012) Edgar Andrés. Estado y Derecho en clave constitucional. Bogotá: Editorial UPTC.

Restrepo Medina, M.(2009) Manual de la acción de tutela. Bogotá: Editorial Intermedio.

República de Colombia. Constitución Política de Colombia 1991.

\section{Sentencias}

Corte Constitucional de Colombia

Sentencia T- 451 de Julio 10 de 1992

Sentencia SU-542 de 1999

Sentencia SU- 960 de 1999

Sentencias T-173/1993

Sentencias T-685/2003

Sentencia T-654/1998

Sentencia C-590 de 2005

Sentencias T-668/1997

Sentencias T.008/1998

Sentencia T-538 de 1994

Sentencia SU-159 de 2002

Sentencia T-705 de 2002

Sentencia T-310 de 2009

Sentencia T-578 de 2010

Sentencia S-105 de 2010

Sentencia S-343 de 2010 